\title{
Experimental Study on the Influence of Heat Treatment on the Structure and Properties of Alloyed Cast Iron with $15 \% \mathrm{Cr}$
}

\author{
Ageel Alogla ${ }^{a}$ \\ ${ }^{a}$ Mechanical Engineering Department, Faculty of Engineering, Taif University, Saudi Arabia.
}

\begin{abstract}
In the current study, the influence of heat treatment on the microstructure, abrasive wear and mechanical properties of high chromium cast iron 3\% Mo was investigated. After hardening heat treatment at of the alloy under investigation at $950{ }^{\circ} \mathrm{C}$, the as cast austenitic structure transformed mostly to martensitic matrix containing fine precipitates of secondary carbides and surrounded by a network of $\mathrm{M}_{7} \mathrm{C}_{3}$ carbides. The holding time at the optimum austenitizing temperature for a specific alloy should be sufficient to ensure the complete precipitation of secondary carbide through all structure of specimen. Experimental results showed that the higher wear resistance and hardness was obtained after hardening at $950^{\circ} \mathrm{C}$ for 120 minutes holding time, followed by air cooling. Increasing sliding wear distances at the load of $30 \mathrm{~N}$ decreased the abrasive wear resistance of the investigated alloy after hardening and tempering heat treatments. Tempering heat treatment after air hardening of the investigated alloy at $400^{\circ} \mathrm{C}$ gave little changes in both hardness and abrasive wear resistance, but tempering treatment at $500^{\circ} \mathrm{C}$ resulted in marked improvements in these properties.
\end{abstract}

Keywords: Heat treatment; Microstructure; Abrasive wear; Holding time; Tempering

\section{INTRODUCTION}

White cast irons are usually very hard and brittle engineering materials, and their hardness can be controlled by an adjustment of the chemical composition. They are most often used in engineering applications where wear resistance is required. Commercially, chromium, molybdenum and nickel are added to unalloyed cast irons to provide improvements generally in the abrasion resistance, toughness and corrosion resistance $[1,2]$. However, the main restriction on their use is extreme brittleness related to the rather high hardness (370 to $580 \mathrm{HV})$. In plain carbon white irons, hardness increases with an increase in the carbon content. Hypoeutectic white irons are the most widely used materials. The high chromium alloyed irons used for wear resistance as specified by ASTM A532 standard are hypo-eutectic and lie in the primary austenite phase field [3,4]. Alloy white cast irons rely on the presence of hard eutectic carbides within their microstructure for wear resistance. The type, proportion and morphology of these eutectic carbides control wear resistance and toughness [5]. Tabrett and Sare [6] reported that the microstructure of the alloy $15 \mathrm{Cr} 3 \mathrm{Mo}$ in the as-cast condition consisted of eutectic carbides in a matrix of austenite and pearlite, with some martensite formation evident around the eutectic carbides. Sare and Arnold [7] stated that the matrix in alloy white cast irons in the as-cast state was primarily austenite. When the cooling rate of the casting was slow enough, a partial transformation of austenite to pearlite or some related forms of ferrite-carbide transformation product might take place. Pearce [3] reported that at low carbon levels (low volume fraction of eutectic carbides) of $15 \%$ Cr irons, where the eutectic carbides are present as a relatively discontinuous interdendritic network, the toughness depended upon the matrix structure. Molybdenum is distributed between the eutectic carbides and the matrix. The addition of small amounts of molybdenum (i.e. $0.5 \%$ Mo ) is sufficient for suppressing pearlite formation particularly when used in combination with other elements such as copper and when the ratio of chromium to carbon (i.e. $\mathrm{Cr} / \mathrm{C})$ is relatively high $[2,8,9]$. The higher chromium content changes the solidification pattern to a structure of $\mathrm{M}_{7} \mathrm{C}_{3}$ carbides surrounded by a matrix of austenite or its transformation products instead of $\mathrm{M}_{3} \mathrm{C}$ carbides that form the matrix $[2,8,10,11,12]$. Pearce [13] stated that in high chromium white irons the higher the chromium content the lower was the carbon content of the destabilized austenite, and then a softer lower carbon martensite was produced on a subsequent transformation. The lower the martensite hardness the more severe was the cracking in the carbides and the more frequent was the removal of broken carbides at the wear surface. The aim of the current investigation is to study the influence of heat treatment on the microstructure, abrasive wear and mechanical properties of high $\mathrm{Cr}$ cast iron containing 3\% Mo. The effect of the austenitizing temperature, holding time and tempering temperature will also considered. The details of microstructure of the investigated alloy were examined by using OM, scanning electron microscope (SEM) and EDS analysis.

\section{EXPERIMENTAL WORK}

\section{II.I. Materials and Heat treatment}

The specimens of high chromium iron containing $15 \%$ Chromium were produced by sand casting technique using an electrical induction furnace of $50 \mathrm{~kg}$ capacity for mechanical and metallographic tests. For the production of the these casting, the wood pattern with dimensions of $25 \times 25 \times 305 \mathrm{~mm}$ were used for making the mold cavity. The pouring temperature of high $\mathrm{Cr}$ cast iron was chosen to be $1480^{\circ} \mathrm{C}$. After casting process, the risers and gates were cut from the castings and the castings were machined and sectioned to prepare the required specimens for the mechanical tests with dimensions of 20x20x20 mm. The chemical composition of high chromium 
Table 1: Chemical composition for the alloys used in the present study

\begin{tabular}{cccccccccccc}
\hline \multirow{2}{*}{$\begin{array}{c}\text { Alloy } \\
\text { designation }\end{array}$} & \multicolumn{10}{c}{ Composition (wt.\%) } \\
\cline { 2 - 12 } & $\mathrm{C}$ & $\mathrm{Si}$ & $\mathrm{S}$ & $\mathrm{P}$ & $\mathrm{Mn}$ & $\mathrm{Ni}$ & $\mathrm{Cr}$ & $\mathrm{Mo}$ & $\mathrm{V}$ & $\mathrm{Fe}$ \\
$15 \mathrm{Cr} / 3 \mathrm{Mo}$ & 1.79 & 0.71 & 0.010 & 0.021 & 0.93 & 0.79 & 14.55 & 2.43 & 0.03 & Bal. \\
\hline
\end{tabular}

cast iron used in the current study is given in Table 1 . All heat treatments (hardening and tempering) of the as-cast alloys were carried out in an electrical muffle furnace. The heat treatment cycle involving hardening and tempering treatments was as follows: First, all specimens were austenitized at different temperatures ranged from 800 to $1000^{\circ} \mathrm{C}$ in order to obtain the austenitic structure. The holding times at these temperatures was 30, 60, 90, 120 and 150 minutes. After that, the specimens were air cooled in still air to room temperature. Finally, the air hardened specimens at $950^{\circ} \mathrm{C}$ were tempered by reheating at temperatures of $300,400,500,600$ and $700^{\circ} \mathrm{C}$ for 90 minuets followed by air cooling down to room temperature.

\section{II.II. Mechanical Tests}

\section{II.II.I. Hardness test}

The specimens of bulk hardness and microhardness measurements were rough ground by using emery paper of (120-400) grit to remove the surface scratches. The bulk hardness measurements were carried out on the specimens with different conditions on Rockwell (scale C) apparatus. Each hardness value was an average of ten readings and was obtained under a major load of $150 \mathrm{~kg}$ and diamond cone indenter. The loading time was 15 seconds. The microhardness of the specimens in the as-cast and heat treated conditions was measured by using Vickers microhardness tester with a load of $100 \mathrm{~g}$. The polished and etched specimens were used for microhardness measurements. An average of five readings was reported in the results.

\section{II.II.II. Wear test}

Wear behavior was estimated by using rotating wheel abrasive testing machine (with rotating speed of steel wheel 28-30 r.p.m) as shown in Figure 1. The specimens on a circular metal track gave a three-body abrasion wear test in which the specimen with a known size and weight was pressed by a normal load on a horizontal rotating steel wheel. Dry abrasive silica sand with an average particle size of 250 to $400 \mu \mathrm{m}$ was fed between the specimen and the rotating wheel. The total wear distance (sliding distance) are 1000, 2000, 3000m. The normal load on the specimens and test time are $3 \mathrm{~kg}$ and one hour, respectively. The abrasive wear of the alloys were measured by their weight loss. The weight loss was obtained by weighting cleaned and dried specimens before and after wear testing by using a threedecimal electronic balance. Each value was obtained from an average of at least two measurements, and the abrasion resistance was expressed by wear index $(($ W.I $)=$ mean weight loss of reference specimen/mean weight loss of tested specimen). The reference specimen was a quenched medium carbon (about $0.43 \%$ C) steel with 54 HRC hardness.

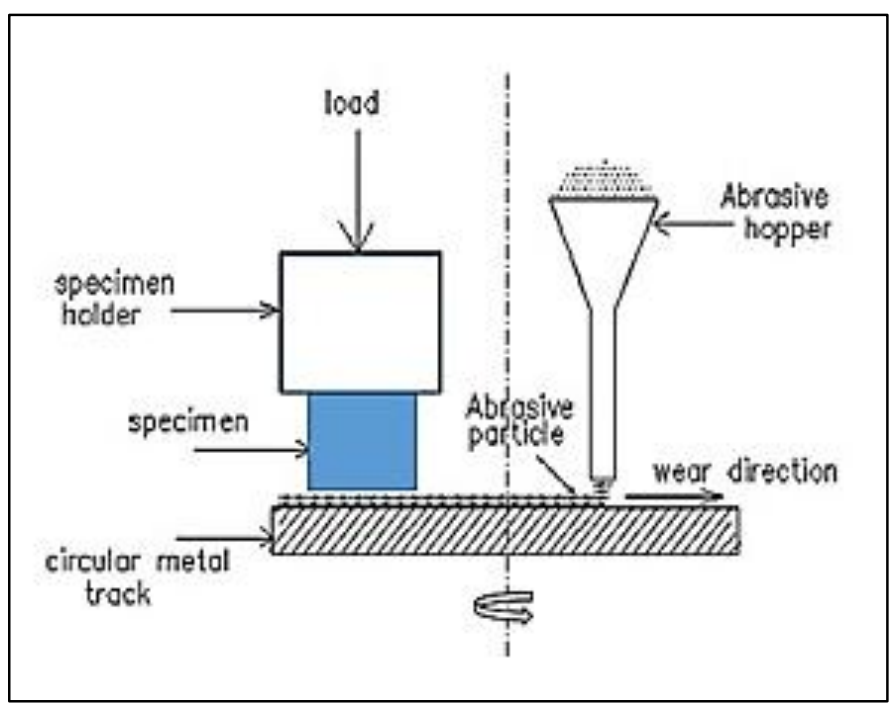

Figure 1: Schematic representation of the three body abrasion test (loaded specimen against rotating steel wheel).

\section{II.III. Metallography}

The specimens used for metallographic examination; either in the as-cast or heat treated conditions, were rough and fine ground to remove distorted surface layers and to give an essentially flat surface by using water proof silicon abrasive emery papers which range from 120 to 1200 grit size. To reveal the microstructure constituents the specimens were etched with $3 \%$ nital solution (3\% nitric acid-97\% ethyl alcohol). After that, the specimens were washed with ethyl alcohol and dried in warm air. The microstructure constituents of the alloys in ascast and heat treated conditions can be identified by using optical microscope, SEM and EDS analysis.

\section{RESULTS AND DISCUSSION}

\section{III.I Microstructure Characterization}

The microstructure of alloyed white cast iron containing $15 \%$ $\mathrm{Cr}$ may be observed from the optical photomicrographs. It was 
well reported that the microstructure of the as-cast alloyed hypoeutectic white cast iron consists of eutectic carbides $\mathrm{M}_{7} \mathrm{C}_{3}$ in a matrix of pearlite or austenite $[3,4,9]$. The optical microstructure of the alloyed white cast irons in the as-cast and heat-treated conditions are shown in Figure2. This figure shows two types of metallic matrix structures in a network of eutectic carbides. The matrix structures can be pearlite, austenite, and martensite or some combination of these. As shown in Figure $2-\mathrm{a}$, the microstructure of the as-cast $15 \% \mathrm{Cr}$ cast iron containing 3\% Mo consists of primary austenite dendrites in a network of eutectic $\mathrm{M}_{7} \mathrm{C}_{3}$ carbides. According to Pearce [3] this microstructure was obtained in the as-cast condition of high $\mathrm{Cr}$ cast irons with high Mo additions. Figure 2 (b, c, d) shows the microstructures of the investigated alloy after heat treatment at 900, 950 and $1000^{\circ} \mathrm{C}$, respectively. From figure 2-b, it is obvious that the microstructure consists of the martensitic matrix containing fine precipitates of secondary carbides in a network of eutectic $\mathrm{M}_{7} \mathrm{C}_{3}$ carbides.

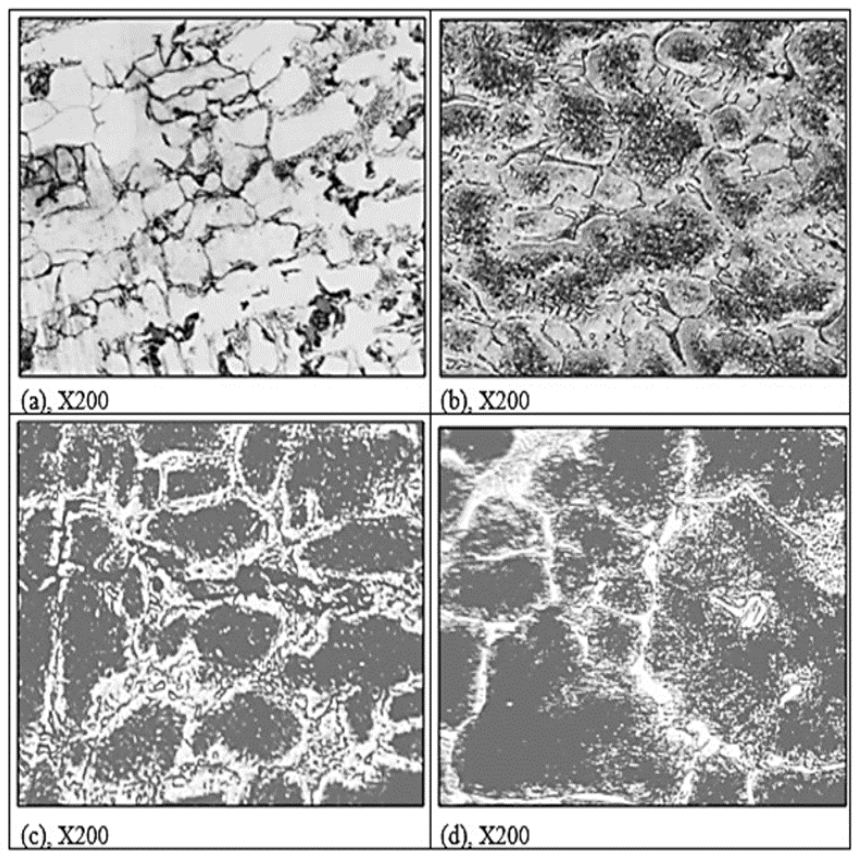

Figure. 2: Optical micrographs show the different microstructures of alloyed cast iron in as-cast and heat treated conditions; (a) as-cast, (b) austenitized at $900^{\circ} \mathrm{C}$, (c) ) austenitized at $950^{\circ} \mathrm{C}$, and (d) ) austenitized at $1000^{\circ} \mathrm{C}$, followed by air cooling.

This microstructure was obtained after air hardening at $900{ }^{\circ} \mathrm{C}$ of alloyed white cast iron under study. In addition, the formation of this structure after air hardening was promoted by high molybdenum addition (i.e. 3\%Mo). The similar microstructures of alloyed cast iron was observed in Figure 2c and Figure 2-d, which also consists of martensitic matrix in eutectic carbides with the presence of secondary carbides. Figure 3 ( $a, b)$ shows SEM and EDS analysis of the investigated alloy cast iron after air hardening at $950{ }^{\circ} \mathrm{C}$, respectively. SEM micrograph in Figure 3-shows the impeded secondary carbides in the martensitic matrix. EDS spectrum of shown in Figure 3-b indicates the chemical analysis of the matrix.

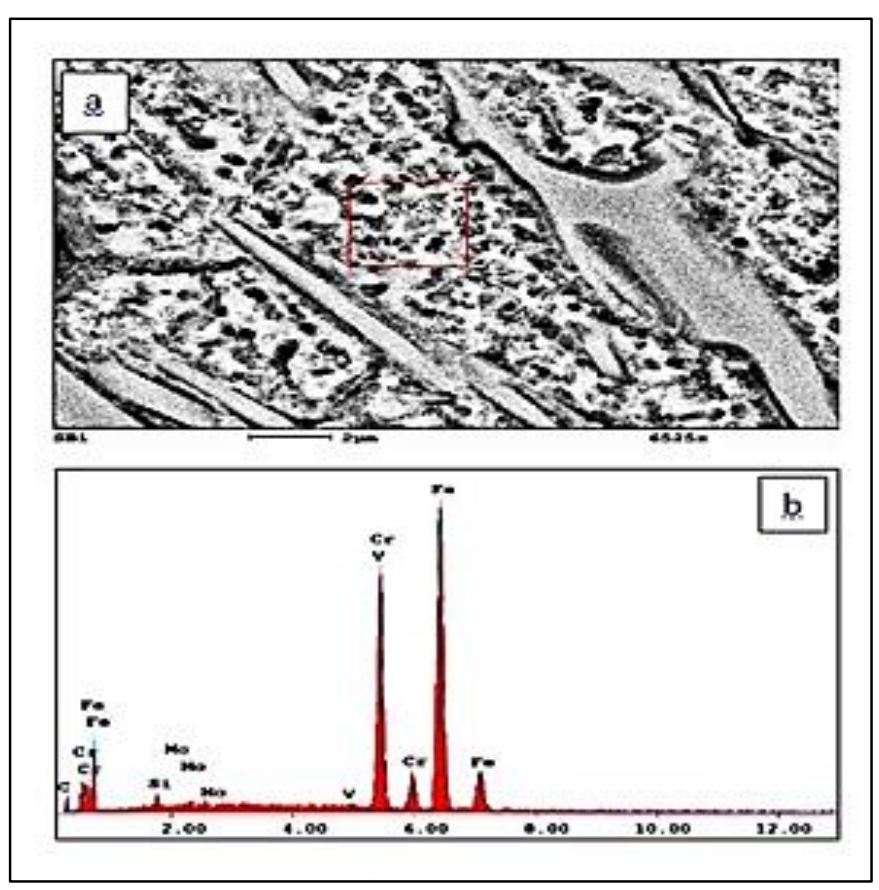

Figure 3: (a) SEM micrographs show secondary carbides in martensitic matrix and (c) EDS analysis of the matrix.

\section{III.II. Influence holding time on the material properties}

Alloyed white cast iron must be heat treated to obtain a martensitic structure and to develop the full hardness for improving their abrasion resistance and toughness. The heat treatment normally consists of heating to a high temperature or austenitizing, air quenching and tempering $[14,15]$. For a given austenitizing temperature the amount of austenite formed increased with the amount of secondary carbides precipitated. At least 1 hour per one inch of section was recommended [3]. Figure 6 indicates the abrasive weight loss of the investigated alloy with different holding times at different sliding distances of 1000,2000 , and $3000 \mathrm{~m}$ at constant load of $3 \mathrm{Kg}$. The total weight loss increased with the increasing the sliding distance at constant load as shown in Figure 4. In the figure, it is clear that the weight loss of the specimen under study decreases markedly with the increasing in holding time to reach to the minimum value at holding time of 120 minutes under $1000 \mathrm{~m}$ sliding distance. This means that the holding time of 120 minutes was sufficient for complete precipitation of secondary carbides. But the increasing in the holding time at austenitizing temperature encourages the retained austenite in the martensitic structure after air hardening. Tabrett and Sare [6] reported that the short holding times with the appropriate destabilization temperature might only be desired to achieve a hardened structure with the maximum hardness. The effect of holding time on the bulk hardness of the investigated alloy is shown in Figure 5. From this figure it is evident also that the hardness after the destabilization heat treatment at $950{ }^{\circ} \mathrm{C}$ of the alloys at holding time of 120 minutes is greater than that in the as cast condition. The short holding times with the appropriate destabilization temperature might only be required to achieve a hardened 
structure with the maximum hardness. For a given holding time, an increase in the destabilization temperature gave an increased retained austenite content, and for a given destabilization temperature an increase in the holding time generally gave an increase in the austenite content [6]. The present results of the hardness, abrasive weight loss and microstructure after heat treatment revealed that the destabilization heat treatment at $950^{\circ} \mathrm{C}$ for 120 minutes holding time has a great influence on the abrasion resistance of the investigated alloy. The abrasive weight loss was found to be lower in the structure with a martensitic matrix than in those with an austenitic matrix at the same carbide volume fraction.

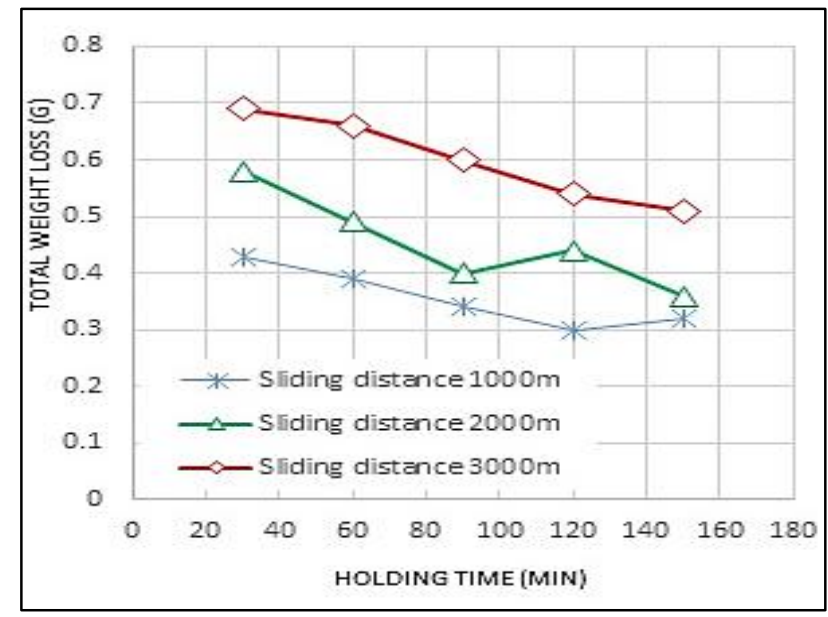

Figure 4: The influence of holding time on the abrasive weight loss (g) at different sliding distances 1000, 2000, and $3000 \mathrm{~m}$ at $950^{\circ} \mathrm{C}$.

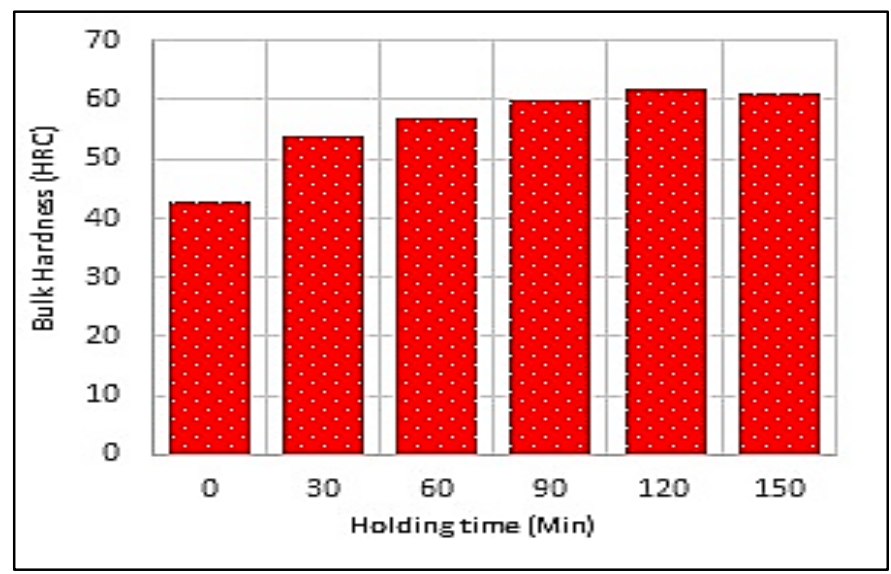

Figure 5: The effect of holding time on the bulk hardness of the investigated alloy at $950^{\circ} \mathrm{C}$.

\section{III.III. Effect of tempering temperature at different sliding distances on the abrasive wear and hardness}

Tempering heat treatment following hardening are commonly utilized to relieve the internal stresses, reduce the levels of retained austenite and to control the final hardness before service. Figures 6 and Figure 7 show the effect of the tempering temperatures at $300,400,500,600$ and $700{ }^{\circ} \mathrm{C}$ on both the microhardness and abrasive weight loss of the air hardened high $\mathrm{Cr} / \mathrm{Mo}$ white cast irons, respectively. The tempering heat treatments at such temperatures produced significant changes in both microhardness and wear performance. In Figure 6, it is evident that the microhardness of the investigated alloy decreased slightly when tempered at $300^{\circ} \mathrm{C}$, but it decreases significantly again after tempering at $400^{\circ} \mathrm{C}$. The hardness of the alloy increased significantly at tempering temperature of $500^{\circ} \mathrm{C}$ and retained approximately the same hardness before tempering. This is due to the secondary hardening effect of these alloys when tempered at $500{ }^{\circ} \mathrm{C}$. Similar behavior (as indicated in Figure 6) of the effect of the tempering temperature on the bulk hardness of the alloyed cast iron under study is presented in Figure 8. This is in agreement with the results of Sare and Arnold [19]. The secondary hardening phenomenon in high chromium white cast irons was thought to be the result of the transformation of austenite to a harder ferrite-carbide aggregate and further transformation of remaining austenite to martensite upon subsequent cooling to room temperature.

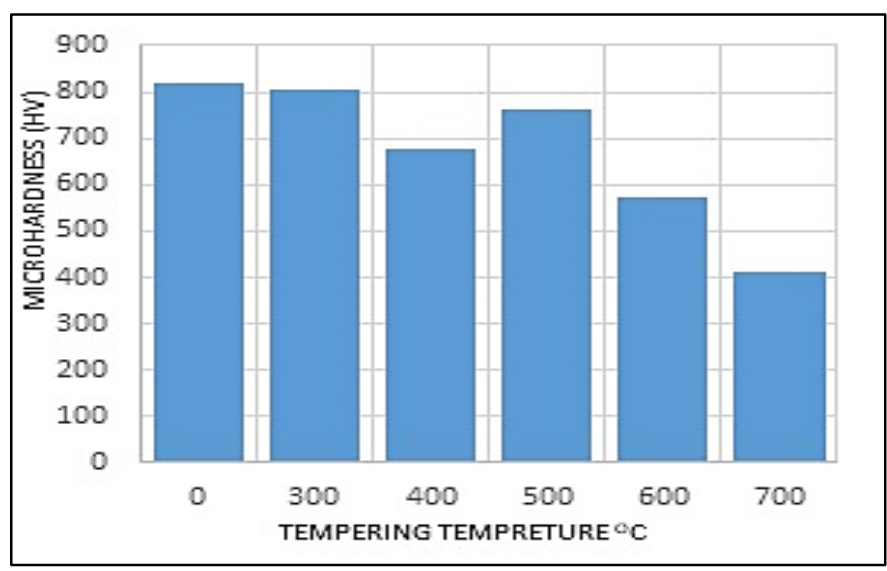

Figure 6: The influence of tempering temperature on the microhardness of air hardened alloy at $950^{\circ} \mathrm{C}$

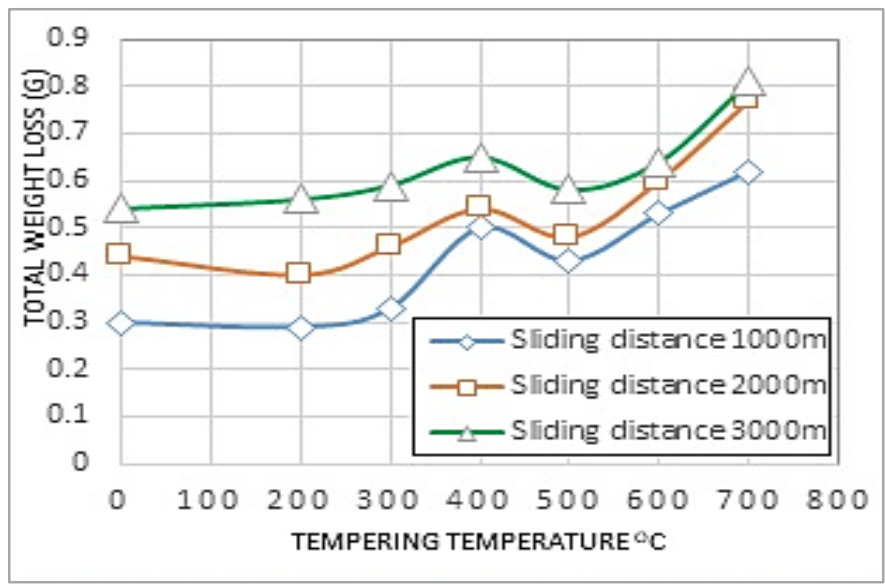

Figure 7: The influence of tempering temperature on the abrasive weight loss $(\mathrm{g})$ of the investigated alloy at different sliding distances of 1000, 2000, and 3000m.

The secondary hardening of the investigated alloy was likely to be a consequence of its relatively high Mo content (i.e. 3\%) and the precipitation of $\mathrm{Mo}_{2} \mathrm{C}$ carbide. The tempering heat treatments above $500{ }^{\circ} \mathrm{C}$ produced noticeable decreases in the 
microhardness and increases in the abrasive weight loss. This is did not reveal any secondary hardening effect. As shown in Figure 8 , the abrasive weight loss increases slightly when the alloys are tempered at $400{ }^{\circ} \mathrm{C}$, but it decreases significantly after tempering at $500^{\circ} \mathrm{C}$ under the different sliding distances of 1000,2000 , and $3000 \mathrm{~m}$ at constant load of $3 \mathrm{Kg}$. The abrasive weight loss of the alloy under study also increases distinctly after tempering above $500^{\circ} \mathrm{C}$ without any symptoms for secondary hardening. The reason for the deterioration of the hardness and abrasion resistance after tempering at $600{ }^{\circ} \mathrm{C}$ and $700{ }^{\circ} \mathrm{C}$ is owing to the decomposition of the retained austenite to ferrite/carbide aggregates. This is in a good agreement with the results of Sare and Arnold [7].

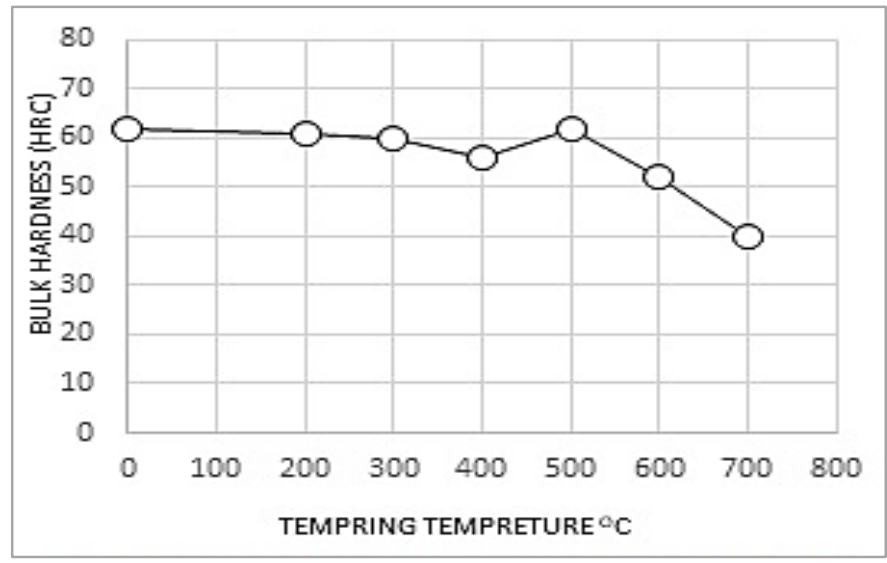

Figure 8: The effect of tempering temperature on the bulk hardness of the investigated alloy

The relationship between the abrasion resistance and both the hardness and microhardness of the investigated alloy in the ascast and heat-treated conditions is indicated in Figure 8. The hardness of microstructure was one of the most important factors which influenced the abrasion resistance [18]. However, hardness alone could not describe wear resistance adequately. In general, the abrasive weight loss increased with decreasing the bulk hardness. From Figure 9 it is clear that the abrasion resistance (as measured by abrasive wear index) increases with increasing both the bulk hardness and microhardness of the investigated alloy. This means that the hardness is a good indicator for the abrasion resistance of the alloyed cast iron in the present study $[18,20]$.

\section{CONCLUSIONS}

The main conclusions from this study are:

- Hardening heat treatment at $950^{\circ} \mathrm{C}$ resulted in significant improvements in both mechanical properties and wear resistance due to the formation of the martensitic matrix surrounded by a network of $\mathrm{M}_{7} \mathrm{C}_{3}$ carbides.

- The higher wear resistance and hardness was obtained after hardening at $950^{\circ} \mathrm{C}$ for 120 minutes holding time, followed by air cooling.

- Increasing sliding wear distances at the load of $30 \mathrm{~N}$ decreased the abrasive wear resistance of the investigated alloy after hardening and tempering heat treatments.

- Tempering heat treatment after air hardening of the investigated alloy at $400^{\circ} \mathrm{C}$ gave little changes in both hardness and abrasive wear resistance, but tempering treatment at $500^{\circ} \mathrm{C}$ resulted in marked improvements in these properties. Nevertheless, these properties deteriorated significantly at higher tempering temperatures due to the decomposition of martensite to ferrite/carbide aggregates.

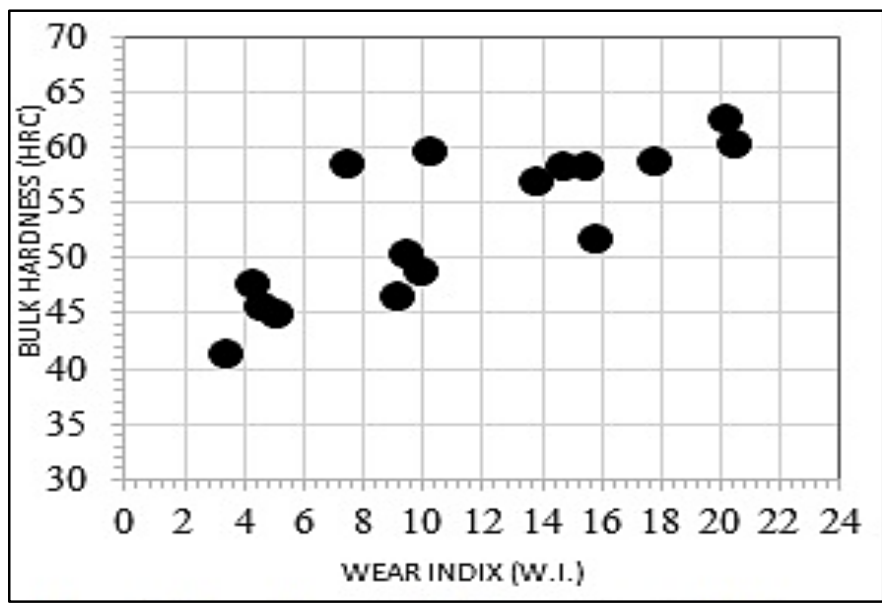

Figure 9: The relationship between matrix bulk hardness and abrasion resistance of the investigated alloy at different conditions.

\section{ACKNOWLEDGMENT}

The author wishes to express my deepest gratitude to Assistant prof. Khaled Abdel Aziz for his help and useful instructions during this research.

\section{REFERENCES}

[1] R.B. Gundlach; "High Alloy White Irons", ASM Hand Book, Casting, $4^{\text {th }}$ Edition, ASM International, Vol. 15, pp. 679-685 (1998).

[2] J.R. Davis "Metallurgy and Properties of High Alloy White Irons", ASM Specially Hand Book, Cast Irons , Materials Park, OH: ASM International, pp. 107-30 (1996).

[3] J.T.H. Pearce; " High-Chromium Cast Irons to Resist Abrasive Wear", Foundryman, Vol. 95 No.4 , pp. 156166 (2002).

[4] R.W. Durman and D.W.J. Elwell, " Morphology Eutectic Carbide in High Chromium White Irons ", British Foundryman, Vol. 78, pp. 371 - 375 (1985).

[5] V. Rajagopal and I. Iwasaki; " Wear Behaviors of Chromium-Bearing Cast Irons in Wet Grinding ", Wear, Vol. 154, pp. 241-258 (1992).

[6] C.P. Tabrett, I.R. Sare, " The Effect of Heat Treatment on The Abrasion Resistance of Alloy White Irons ", Wear, Vol. 203-204, pp. 206-219 (1997). 
[7] I.R. Sare and B.K. Arnold; " The Effect of heat Treatment on The Gouging Abrasion Resistance of Alloy White Cast Irons", Metallurgical and Materials Transactions A, Vol. 26A, PP. 357-370 (1995).

[8] Metals Hand Book, Properties and Selection of Iron and steels, 9th Edition, Metals Park, OH: ASM International, Vol. 1, pp. 76-96 (1960).

[9] X. Huang; " The Effect of Mo on The Structure of High Cr-Mo Alloy Iron ", Journal of Materials Engineering and Performance, Vol.10 No.5, pp. 592-595 (2001).

[10] R.B. Gundlach and D.V. Doane; " Heat Treating of High Alloy Irons", ASM Hand book, Heat Treating, 4th Edition, ASM International,Vol.4, pp. 697-708 (1991).

[11] Kh. Abd El-Aziz. Kh. Zohdy. D. Saber. H. E. M. Sallam," Wear and Corrosion Behavior of High-Cr White Cast Iron Alloys in Different Corrosive Media" J Bio Tribo Corros, 1, 25-37(2015).

[12] Sallam HEM, Abd El-Aziz Kh, Abd El-Raouf H, Elbanna EM, "Flexural strengthand toughness of austenitic stainless steel reinforced high-Cr white cast iron composite", J Mater Eng Perform 22,(2013), (12):3777.

[13] J.T.H. Pearce, "Abrasive Wear Behavior of Alloy Cast Irons", British Foundry man, Vol. 78, pp. 13-23 (1985).

[14] J.M. Bereza, " Wear and Impact Resistant White Cast Irons ", British Foundryman, Vol. 74, pp. 205-211 (1981).

[15] Kh. Abdel-Aziz, M. El-Shennawy and Adel A. Omar, "Microstructural Characteristics and Mechanical Properties of Heat Treated High-Cr White Cast IronAlloys", International Journal of Applied Engineering Research ISSN 0973-4562 Volume 12, Number 14 (2017) pp. 4675-4686.

[16] Marıa Agustina Guitar, Sebastian Suarez, Orlando Prat, Martın Duarte Guigou, Valentina Gari, Gaston Pereira, and Frank Mu cklich, "High Chromium Cast Irons: Destabilized-Subcritical Secondary Carbide Precipitation and Its Effect on Hardness and Wear Properties", JMEPEG (2018) 27:3877-3885.

[17] X. Huang and Y. Wu; "A High Cr-Mo Alloy Iron ", Journal of Materials Engineering and Performance, Vol. 7 No. 4, pp. 463-466 (1998).

[18] K.H.Z. Gahr and G.T. Eldis; "Abrasive Wear of White Cast Irons", Wear, Vol. 64, pp. 175-194 (1980).

[19] I.R. Sare and B.K. Arnold; "The Influence of Heat Treatment on The High Stress Abrasion Resistance and Fracture Toughness of Alloy White Cast Irons", Metallurgical and Materials Transactions A, Vol. 26A, pp. 1785-1793 (1995).

[20] O.N. Dogan, J.A. Hawk and G. Laird II; "Solidification Structure and Abrasion Resistance of High Chromium White Irons", Metallurgical And Materials Transactions A, Vol. 28A No.6, pp. 1315-1328 (1997). 